\title{
China and HIV Vaccine Research: An Old Country with a New Commitment Yunda Huang ${ }^{1 *}$, Steven G. Self ${ }^{1,2}$ and Yiming Shao ${ }^{3}$ \\ ${ }^{1}$ Statistical Center for HIVIAIDS Prevention and Research, Vaccine and Infectious Disease Division, Fred Hutchinson Cancer Research Center, Seattle, USA ${ }^{2}$ Department of Biostatistics, University of Washington, Seattle, USA \\ ${ }^{3}$ National Center for AIDS/STD Control and Prevention, Chinese Center for Disease Control and Prevention, Beijing, China
}

In 2010, China invested approximately US $\$ 18.3$ million in HIV vaccine research and development, becoming the third largest HIV vaccine funder globally, behind the United States' investmentof \$859 and the European Commission's investment of US\$18.5 [1,2]. Recently, the Chinese government has also pledged to further boost funding for HIV vaccine development by at least 20 percent in 2011-2015 in its twelfth five-year plan [3]. Despite other countries' decreasing funding, such as the US with the largest decline of US \$ 17 million from 2009 to 2010, China has been going against the trend by investing significantly more money in HIV vaccine research. Why is China doing this? What is the outlook of China's role in the global search of an effective vaccine against HIV? Let's look at the HIV/AIDS epidemic and HIV vaccine research in China to try to answer these questions.

\section{HIV/AIDS in China}

Since its first AIDS case was identified in 1985, China's HIV/AIDS epidemic has expanded in size and spread in regions throughout the country. By 2002, HIV-positive people were present in all Chinese mainland provinces, municipalities, and autonomous regions [4]. In 2008, AIDS became China's number one killer infectious disease [5]. Joint research by the Health Ministry of China and WHO estimated total HIV infection cases of 0.74 million, with more than 0.13 million AIDS cases in China in 2010 [6]. In 2011, more than 48,000 new HIV infections were reported, and mortality from AIDS was almost 30,000 [7].

Although China's HIV epidemic remains at low prevalence overall $(0.1 \%$ among adults) given its large population size, considerable concerns have been raised to the public and government officials regarding pockets of high infection rates among several sub-populations including Former Plasma Donors (FPD), Injecting Drug Users (IDU), Men who have Sex with Men (MSM), and most recently discordant heterosexual couples (DHC). HIV transmission in FPDs was greatly reduced after the banning of unregulated commercial blood collection in 1996 [8,9]. However, in IDU populations, HIV prevalence of more than $20 \%$ was reported in cities along or close to the drug trafficking road in the Province of Yunnan, Xinjiang, Sichuan, Guizhou, Hunan and Guangxi in 2004 [7]. A cohort study conducted between 20022005 reported an HIV incidence rate of 2.3 per 100 person-years in a drug trafficking city in southwest China [10]. In MSM populations, HIV transmission through homosexual sex accounts for $42 \%$ of new infectionsin 2009 [11] with an alarmingly high incidence rate of 5-8 per 100 person-years in some regions of China such as Shenyang [12] and Beijing [13]. The epidemic continues to spread further into the general population mostly through heterosexual transmission. In 2009 around 42 percent of people newly infected with HIV became infected through heterosexual sex [11]. A meta-analysis of heterosexual transmission among HIV discordant couples in China estimated an HIV seroconversion rate of 1.2 (95\% CI: $0.9-1.7)$ per 100 person-year with an overall prevalence estimate of $11.5 \%$ (95\% CI: 8.2\% - 15/2\%) for HIV prevalence through heterosexual transmission in discordant couples [14].

These statistics have resulted in enormous pressure on the Chinese government to carry out effective prevention and imperative control of the HIV/AIDS epidemic in China. In the 1950's, the newly established People's Republic also faced serious public health challenges when $10 \%$ of national minorities, $5 \%$ of Chinese city dwellers and $2-3 \%$ of Chinese rural residents had syphilis, and the majority of sex workers living in urban areas had one or more Sexually Transmitted Diseases (STDs) [15,16]. The Chinese government was able to achieve virtual eradication of sexually transmitted diseases by massive health campaigns that were mostlyportrayed as patriotic [17]. However, today the value of freedom, personal wealth and happiness, as influenced by western culture since China reopened its doors to the west in the 1980's, often dominates the public's patriotic emotions towards government's campaigns. The government also realized that propaganda of drastic measures that worked before is no longer as effective to solve public health problems in China $[18,19]$. As a result, more science-based strategies have been implemented in China. For example, reduction of HIV transmission has been observed among the IDU populations due to the government's few strategies including the implementation of needle exchange programs since 1999 [20,21] and Methadone maintenance treatment programssince 2004 [22,23]. However, effective interventions among other high risk groups have been difficult to reach high coverage primarily due to their massiveness and underground nature. Discordant heterosexual couples are partially hidden and hard to reach because they are mainly comprised of migrant workers, their families, under-ground sex workers and their clients, and, covert gay men and their wives. Although homosexuality is becoming more tolerated in the cities, MSMs are often in a heterosexual marriage to conceal their true sexual orientation due to high levels of stigma toward homosexual sex in the Asian culture.

\section{HIV Vaccine Research in China}

More recently, the Chinese government realized the development of a safe and effective HIV vaccine could provide the best hope to control the HIV/AIDS epidemic, particularly among those hardto-reach risk groups and in resource-constrained regions. Such a commitment was highlighted during a visit to China CDC by Chinese Premier Wen Jiabao on the World AIDS Day in 2011, when he stressed on the importance of HIV vaccine research [24]. Such a strong political commitment in China often translates into important financial support.

*Corresponding author: Yunda Huang, PhD, Senior Staff Scientist, Statistical Center for HIVIAIDS Prevention and Research, Vaccine and Infectious Disease Division, Fred Hutchinson Cancer Research Center, 1100 Fairview Ave. N, M2C200, Seattle, 98109-1024 USA, Tel: 206-667-5780; Fax 206-667-4378; E-mail: yunda@scharp.org

Received May 16, 2012; Accepted May 18, 2012; Published May 22, 2012

Citation: Huang Y, Self SG, Shao Y (2012) China and HIV Vaccine Research: An Old Country with a New Commitment. J AIDS Clinic Res 3:e106. doi:10.4172/2155$6113.1000 \mathrm{e} 106$

Copyright: (c) 2012 Huang Y, et al. This is an open-access article distributed under the terms of the Creative Commons Attribution License, which permits unrestricted use, distribution, and reproduction in any medium, provided the original author and source are credited. 


\begin{tabular}{|l|l|l|}
\hline Researcher /Developer & Vaccine candidate & Development stage \\
\hline Jilin University & DNA/MVA & Phase II \\
\hline $\begin{array}{l}\text { National Center for AIDS/STD } \\
\text { Control and Prevention, China } \\
\text { CDC }\end{array}$ & DNA/TiantanVaccinia & Phase II \\
\hline Institute of Virology, China CDC & DNA/MVA (therapeutic) & Phase I \\
\hline $\begin{array}{l}\text { Tsinghua University, Hongkong } \\
\text { University, Chinese Academy of } \\
\text { Science }\end{array}$ & $\begin{array}{l}\text { Modified TiantanVaccinia/ } \\
\text { Nanjing Medical University }\end{array}$ & Pre-clinical \\
\hline $\begin{array}{l}\text { Shanghai Pasteur Institute, Chi- } \\
\text { nese Academy of Science }\end{array}$ & DNA + gp120 $/$ LPP & Pre-clinical \\
\hline
\end{tabular}

Table 1: Ongoing Pre-clinical and Clinical Trials of HIVIAIDS Vaccine in China.

Specifically, China has targeted AIDS vaccine research in its National Key Science and Technology projects to encourage Chinese scientists and institutions to participate in international collaboration. In the newly released Eleventh Five-Year plan (2011-2015), AIDS vaccine research was again set as an important special-funded area in the infectious diseases prevention and control mega science and technology projects. Such a position in the country's strategic planning suggests China's capability and willingness to shoulder more responsibility in HIV vaccine research especially after it overtook Japan to become the world's second-largest investor in R\&D after the United States in 2009 [25]. In the same year, six Chinese AIDS vaccine research teams from 28 institutes established the China AIDS Vaccine Initiative (CAVI) to work together on AIDS vaccine research and collaborate with international partners [26-28]. Meanwhile, the Chinese government has also planned to sponsor China's first large scale HIV vaccine trial to evaluate the efficacy of the vaccine candidate in high risk population in 2014-2015, adding to the short list of five HIV vaccine efficacy trials that have been conducted so far in the past 30 years [29-33]. Recently, China's Natural Science Foundation has provided joint funding with the US National Institute of Health (NIH) to support an international collaboration between Chinese and US researchers on the design and planning of this trial [34].

Although a short list, HIV vaccine candidates in the pipeline for evaluation in China (Table 1) expands the diversity of vaccine products in the global HIV vaccine research community. Particularly, scientists at China CDC are currently evaluating the safety and immunogenicity of recombinant DNA boosted by replicating Tiantan Vaccinia virus vector (rTV) with HIV gene inserts from HIV-1 CN54(B'/C) in a Phase IIa clinical trial among high risk MSMs [35]. China's self-developed HIV vaccine candidate, DNA + rTV, has been proven to be safe and immunogenic in Phase Ia and Ib clinical trials [36,37]. Given that the vast majority of HIV vaccine resources are currently devoted to development and testing of non-replicating vector vaccines [38], findings from such a trial is expected to be of high interest to the HIV vaccine research community worldwide.

In addition, with dominant HIV circulating strains of CRF01_AE, CRF07_B'C, and subtype B [39], China is in a unique bridging position to translate findings in China to other regions of the world that share common HIV subtypes in the circulating strains, including Latin America, North America, the Caribbean and Western Europe. Given its massive population and often centralized and well-equipped clinical sites and laboratory facilities, China is also in a unique position to speed up the evaluation of HIV vaccine candidates with strong commitment from its government.

The outlook of HIV vaccine research in China does not only have its rosy side; there are certainly challenges in effectively engaging China within the global HIV vaccine research realm. The Chinese government calls for more international collaborations in HIV vaccine research and has taken it seriously. For example, every other year China has held a high level international AIDS meeting and conducted national HIV/AIDS estimates and program evaluations with the Joint United Nations Programme on HIV/AIDS(UNAIDS) and the World Health Organization (WHO) since 2005. Large national HIV vaccine programs, such as the Comprehensive International Program for Research on AIDS (CIPRA) and CAVI, invited prominent foreign scientist as chairs and members on their Scientific Advisory Board, with active engagement from major international agencies and organizations including UNAIDS, WHO, US National Institute of Health, Bill and Melinda Gates Foundation, HIV Vaccine Trials Network and the International AIDS Vaccine Initiative. However, China still often receives criticism for being guarded in information sharing with international collaborators. While there may be a greater need of transparency and openness from the Chinese government and scientists to collaborate with international stakeholders, there is also a need for foreign governments and organizations to better understand the cultural and societal background in China's research community. For example, historically dominated by a largely shame-based Confucian culture in which "... men hesitated to speak, for if their conduct fall short of what is said, it would be shameful." (Analects of Confucius 4: 22), China is still "culturally-inclined" to cautiously share "uncertain" information with outsiders. This caution, however, should not be confused with an unwillingness to collaborate. Investment in a collaborative relationship of mutual trust and understanding with clear and common research goals can result in an openness of information sharing sufficient to support the collaboration. Another challenge is that China, being more frequently in the spotlight for economic growth and human rights, has a strong desire to make impact on its own effort. Although not unique to China, this certainly requires nuance and sensitivity in handling international collaboration with China. Last but not least, relatively tight regulatory requirements on early phase human clinical trials may also place constraints on the development of a successful HIV vaccine in China.

Nevertheless, China is a large and open country that possesses sufficient social and political motivations, as well as financial resources and scientific capability to play an important and unique role in the global search for an effective vaccine against HIV. Although the discovery of a successful HIV vaccine may seem elusive after three decades of concerted effort, the HIV vaccine field must not despair especially given the development of a successful vaccine had typically required decades to accomplish. China is now poised to fully engage its considerable resources in this effort and take its place among the global leaders in the search for a safe and effective HIV vaccine. This could not come at a better time.

\section{Acknowledgements}

We thank Abbe Lynn and Lily Zhang for editorial assistance. Grant support NOT-CA-11-003 US-China Biomedical Collaborative Research NIAID 5 U01 Al068635 Administrative Supplement.

\section{References}

1. (2011) China sets more funds for HIV research.

2. Shan $\mathrm{J}$ (2011) Funding for HIV vaccine research on the rise.

3. Gang P (2011) China's Wen delivers key targets of its development.

4. (2010) 2009 Estimates for the HIV/AIDS Epidemic in China.

5. Mu X (2009) AIDS ranks top fatal infection among Chinese in 2008. 
Citation: Huang Y, Self SG, Shao Y (2012) China and HIV Vaccine Research: An Old Country with a New Commitment. J AIDS Clinic Res 3:e106. doi:10.4172/2155-6113.1000e106

Page 3 of 3

6. Wang N, Wang L, Wu Z, Guo W, Sun X, et al. (2010) Estimating the number of people living with HIV/AIDS in China: 2003-09. Int J Epidemiol 39: ii21-ii28.

7. China CDC (2004) Chinese Center for Disease Control and Prevention National Sentinel Surveillance Report of HIV Infection.

8. Li N, Wang Z, Sun D, Zhu Q, Sun G, et al. (2010) HIV among plasma donors and other high-risk groups in Henan, China. J Acquir Immune Defic Syndr 53: S41-S47.

9. UNAIDS (2002) HIVIAIDS: China's Titanic Peril.

10. Ruan Y, Qin G, Yin L, Chen K, Qian HZ, et al. (2007) Incidence of HIV, hepatitis $\mathrm{C}$ and hepatitis $\mathrm{B}$ viruses among injection drug users in southwestern China: a 3-year follow-up study. AIDS 21: S39-S46.

11. UNGASS (2010) China 2010 UNGASS Country Progress Report (2008-2009).

12. Xu JJ, Zhang M, Brown K, Reilly K, Wang H, et al. (2010) Syphilis and HIV seroconversion among a 12-month prospective cohort of men who have sex with men in Shenyang, China. Sex Transm Dis 37: 432-439.

13. Li HM, Peng RR, Li J, Yin YP, Wang B, et al. (2011) HIV incidence among men who have sex with men in China: a meta-analysis of published studies. PLoS One 6: e23431.

14. Wang L, Peng Z, Li L, Norris JL, Cao W, et al. (2012) HIV seroconversion and prevalence rates in heterosexual discordant couples in China: A systematic review and meta-analysis. AIDS Care.

15. Cohen MS, Henderson GE, Aiello P, Zheng H (1996) Successful eradication of sexually transmitted diseases in the People's Republic of China: implications for the 21st century. J Infect Dis 174: S223-S229.

16. Hershatter G (1997) Dangerous pleasures: prostitution and modernity in twentieth-century Shanghai: University of California Press.

17. Shao Y, Wu J (2012) Historical Foundations and Future Directions of China's HIVIAIDS Strategy AAAS. Vancouver, Canada.

18. Wu Z, Wang Y, Mao Y, Sullivan SG, Juniper N, et al. (2011) The integration of multiple HIVIAIDS projects into a coordinated national programme in China. Bull World Health Organ 89: 227-233.

19. Human Rights Watch (2003) Locked doors: the Human rights of people living with HIVIAIDS in China.

20. Liu B, Sullivan SG, Wu Z (2007) An evaluation of needle exchange programmes in China. AIDS 21: S123-S128.

21. IHRA (2010) Global State of Harm Reduction 2010

22. Wu Z (2005) Methadone maintenance program in mainland China: from pilot to scale-up. International Conference on the Reduction of Drug Related Harm. Belfast, UK.

23. Wu Z, Li J (2004) Landmark government methadone maintenance program in mainland China. 15th International AIDS Conference. Bangkok, Thailand.

24. CNTV (2011) Wen Jiabao visits CCDCP, attends AIDS symposium.

25. Qiu J (2012) China’s budget backs science. Nature 483: 258.
26. Pitisuttithum P, Rerks-Ngarm S, Chiu J, Kim J, Benenson M, et al. (2011) Accelerating the development of an AIDS vaccine: the AIDS vaccine for Asia Network (Avan). Southeast Asian J Trop Med Public Health 42: 1130-1146.

27. Kent SJ, Cooper DA, Chhi Vun M, Shao Y, Zhang L, et al. (2010) AIDS vaccine for Asia Network (AVAN): expanding the regional role in developing HIV vaccines. PLoS Med 7: e1000331.

28. Rerks-Ngarm S, Pitisuttithum P, Ganguly N, Zhang L, Tamashiro H, et al (2010) Defining the objectives of the AIDS vaccine for Asia network: report of the WHO-UNAIDS/Global HIV vaccine enterprise regional consultation on expanding AIDS vaccine research and development capacity in Asia. Curr Opin HIV AIDS 5: 435-452.

29. Flynn NM, Forthal DN, Harro CD, Judson FN, Mayer KH, et al. (2005) Placebocontrolled phase 3 trial of a recombinant glycoprotein 120 vaccine to prevent HIV-1 infection. J Infect Dis 191: 654-665.

30. Pitisuttithum P, Gilbert P, Gurwith M, Heyward W, Martin M, et al. (2006) Randomized, double-blind, placebo-controlled efficacy trial of a bivalent recombinant glycoprotein $120 \mathrm{HIV}-1$ vaccine among injection drug users in Bangkok, Thailand. J Infect Dis 194: 1661-1671.

31. Buchbinder SP, Mehrotra DV, Duerr A, Fitzgerald DW, Mogg R, et al. (2008) Efficacy assessment of a cell-mediated immunity HIV-1 vaccine (the Step Study): a double-blind, randomised, placebo-controlled, test-of-concept trial. Lancet 372: 1881-1893.

32. Gray GE, Allen M, Moodie Z, Churchyard G, Bekker LG, et al. (2011) Safety and efficacy of the HVTN 503/Phambili study of a clade-B-based HIV-1 vaccine in South Africa: a double-blind, randomised, placebo-controlled test-of-concept phase 2b study. Lancet Infect Dis 11: 507-515.

33. Rerks-Ngarm S, Pitisuttithum P, Nitayaphan S, Kaewkungwal J, Chiu J, et al (2009) Vaccination with ALVAC and AIDSVAX to prevent HIV-1 infection in Thailand. N Engl J Med 361: 2209-2220.

34. Huang Y, Self S, Gilbert P, Yao L, Shao Y (2012) US-China Collaborations on the Design of China's first Phase IIb HIV Vaccine Efficacy Trial. Society for Clinical Trial Annual Meeting. Miami, USA.

35. Huang Y, Self S, Shao Y (2012) Ranking and Selection Design of a Phase Ila HIV Vaccine Clinical Trial in China with Three Active Arms and Multiple Immunogenicity Trial Endpoints. Society for Clinical Trial Annual Meeting Miami, USA.

36. Shao Y, Li T, Shen X, Zhang J, Zhu H (2008) The safety and immunogenicity of the replicative Tiantan vaccinia HIV vaccine in phase I clinical trial. AIDS Vaccine 2008. Cape Town, South Africa.

37. Shao Y, Li T, Wolf H, Liu Y, Wang $H$ (2009) The safety and immunogenicity of HIV-1 vaccines based on DNA and replication competent vaccinia vector in phase I clinical trial. AIDS Vaccine 2009. Paris.

38. Excler JL, Parks CL, Ackland J, Rees H, Gust ID, et al. (2010) Replicating viral vectors as HIV vaccines: summary report from the IAVI-sponsored satellite symposium at the AIDS vaccine 2009 conference. Biologicals 38: 511-521.

39. Teng T, Shao Y (2011) Scientific approaches to AIDS prevention and control in China. Adv Dent Res 23: 10-12. 